TẠP CHÍ KHOA HỌC ĐẠI HỌC TÂN TRÀO

ISSN: $2354-1431$

http://tckh.daihoctantrao.edu.vn/

\title{
Thế giới loài vật trong truyện viết cho thiếu nhi của một số nhà văn dân tộc thiểu số Việt Nam hiện đại
}

\author{
Cao Thị Hảo ${ }^{a^{*}}$ \\ ${ }^{a}$ Truò̀ng Đại học Su phạm Thái Nguyên \\ *Email: caohaokv@gmail.com
}

\section{Thông tin bài viết}

Ngày nhận bài:

$06 / 02 / 2018$

Ngày duyệt đăng:

$10 / 3 / 2018$

\section{Tù khoá:}

Văn học dân tộc thiểu số; Văn học thiếu nhi; Giáo dục trẻ em; Thế giói loài vật.

\section{Tóm tắt}

Bài viết đề cập đến đóng góp của một số tác giả dân tộc thiểu số cho mảng văn học thiếu nhi khi viết về thế giới loài vật gần gũi với trẻ em miền núi. Các nhà văn dân tộc thiểu số đã mang vào trong trang văn viết cho thiếu nhi của mình những nét tiêu biểu nhất của cảnh sắc và con người miền núi, đặc biệt là thế giới loài vật vô cùng gần gũi, đáng yêu. Trong truyện viết cho thiếu nhi của một số tác giả tiêu biểu như: Mã $\mathrm{A}$ Lềnh, Vi Hồng, Đoàn Lư..., độc giả nhỏ tuổi tìm thấy cho mình những bài học bổ ích, sâu sắc về tình yêu loài vật, con người, tình yêu lao động và những trải nghiệm thú vị với những kỉ niệm khó quên. Đó cũng là những bài học giáo dục cho các em về lẽ phải và cách làm người sâu sắc, ý nghĩa. Đây có thể coi là nguồn tài liệu phong phú, đa dạng cho các cấp Tiểu học và Mầm non ở các địa phương miền núi phía Bắc. Tuy nhiên, hiện nay nguồn tư liệu này chưa được chú trọng để đưa vào tiếp nhận trong các nhà trường phổ thông.
1. Trong văn học thiếu nhi Việt Nam, các độc giả đã quen thuộc với những câu chuyện về loài vật rất đáng yêu trong tác phẩm của Tô Hoài, Phạm Hổ, Võ Quảng, Trần Đăng Khoa hay gần đây là trong sáng tác của Nguyễn Nhật Ánh... Viết cho thiếu nhi, các nhà văn thường mượn chuyện loài vật để nói chuyện con người, để đưa ra những bài học giáo dục nhân cách, lối sống. Đến với sáng tác cho thiếu nhi của các nhà văn dân tộc thiểu số, độc giả nhí cũng sẽ được làm quen với những loài vật gắn bó, gần gũi với trẻ em dân tộc và miền núi.

2. Truyện viết cho thiếu nhi của các nhà văn dân tộc thiểu số đã có một số tác giả quan tâm, như: Lã Thị Bắc Lý (với bài viết: Văn học thiếu nhi Việt Nam từ thời kì đổi mới, in trong cuốn: Văn học Việt Nam sau 1975 những vấn đề nghiên cứu và giảng dạy, $\mathrm{Nxb}$ Giáo dục, 2006), Cao Thị Hảo (Diện mạo văn học thiếu nhi dân tộc thiểu số Việt Nam hiện đại (Tạp chí Nghiên cứu Văn học, số 7/2016), nhóm tác giả Đào Thuỷ Nguyên, Cao Thị Hảo, Lý Thị Nhâm (Mã A
Lềnh và văn xuôi thiếu nhi dân tộc thiểu số Việt Nam hiện đại, Tạp chí Diễn đàn văn nghệ Việt Nam, số 258, tháng 7/2016). Trong bài viết: Truyện của Kim Nhất, tác giả Lâm Tiến bước đầu đã giới thiệu về các sáng tác viết cho thiếu nhi của nhà văn ở miền Nam Tây Nguyên này bằng một nhận xét ngắn gọn: "Truyện viết về các loài vật của Kim Nhất như Con cộ, Chú voi trung thành, Loài cọp biết đùa, Chúa sơn lâm mắc bẫy... nội dung thường rõ ràng, dễ hiểu, có ý nghĩa giáo dục nhất định, rất thích hợp với lứa tuổi thiếu nhi" [9; tr.97].

Nhìn chung, các bài nghiên cứu trên mới quan tâm đến văn học viết cho thiếu nhi của các nhà văn dân tộc thiểu số. Vấn đề về thế giới loài vật được phản ánh trong các tác phẩm văn học dân tộc thiểu số viết cho thiếu nhi vẫn chưa được tìm hiểu một cách hệ thống, cụ thể mà mới dừng lại ở những đánh giá, nhận xét chung.

3. Các nhà văn dân tộc thiểu số đã mang vào trong trang văn viết cho thiếu nhi của mình những 
nét tiêu biểu nhất của cảnh sắc và con người miền núi. Đặc biệt với các em thiếu nhi, thế giới loài vật vô cùng gần gũi, đáng yêu. Đó là những người bạn tốt bụng, gan dạ, dũng cảm và đó cũng là nơi tuổi thơ được trải qua những giờ phút thú vị, êm đềm khi được hòa mình vào thiên nhiên nên thơ tươi đẹp, được đón nhận nhưng món quà do thiên nhiên ban tặng.

Khác với Tô Hoài (viết về thế giới của những con vật quen thuộc với trẻ em nông thôn Việt Nam miền xuôi như: Dế mèn, Bọ ngựa, con chó, con mèo, con chuột, con lợn, con gà, con ngỗng, con dê, con sáo sậu, con chim chèo bẻo, con chim gáy, bồ nông,...), các tác giả dân tộc thiểu số lại tập trung miêu tả những loài vật gần gũi, gắn bó với trẻ em vùng cao, miền núi như con trâu, con ngựa, chú chó săn...

Trong sáng tác cho thiếu nhi của Mã A Lềnh, những tác phẩm viết về loài vật có ý nghĩa đặc biệt quan trọng. Trong hai tập truyện ngắn Dấu chân trên đường và Thằng bé củ mài, ông đã viết 6/18 truyện về những con vật thông minh, tình nghĩa. Thế giới loài vật được ông miêu tả chủ yếu là những con vật gần gũi thân quen với con người như: con trâu Pù Suô (Cuộc chiến bất ngờ), con trâu Sừng Săn (Núi Cu Sú), con ngựa Mun (Con ngựa mun cuối cùng thuộc dòng dõi quý tộc), con chó săn tên Cộc (Đi săn),... Mỗi con vật đều được khoác lên mình những nét tính cách độc đáo, sống động lạ lùng. Ngòi bút tài tình của ông lột tả được những nét đặc sắc của đối tượng qua những chi tiết chân thực, nét vẽ cụ thể, điệu bộ tự nhiên và cả thế giới nội tâm ngộ nghĩnh, gần gũi với các em nhỏ dân tộc miền núi.

Với trẻ em miền núi, tuổi nhỏ làm việc nhỏ, các em thường chăn trâu, bò, ngựa giúp gia đình nên những con vật này hết sức gần gũi và trở thành người bạn tốt của tuổi thơ. Hai con trâu Pù Suô và Sừng Săn được nhân vật "tôi" chăn dắt từ nhỏ và hết mực yêu quý. Pù Suô là một con trâu cái "răng trắng", "mập mạp", "da bóng nhoáng", được mua về khi còn gầy nhòm, xấu xí. Là một con trâu đã nhiều tuổi, Pù Suô có sự suy tư, chững chạc như một con người từng trải qua bao sóng gió. Khi miêu tả con Pù Suô, Mã A Lềnh đặc biệt chú ý đến việc thể hiện những diễn biến tâm lí phức tạp của nó. "Cuộc nghênh chiến ngấm ngầm giữa con Mộng Non của nhà anh Páo và con Mộng Trung của nhà anh Chảo. Con Pù Suô biết rất rõ điều đó... Nó vừa đi vừa ngẩng cao đầu, dò $\mathrm{la}$, nghe ngóng. Chừng như nó muốn nói với tôi, với cả đàn trâu rằng sắp sửa có một cuộc quyết chiến" [4, tr14]. Quả nhiên, cuộc quyết chiến đó đã xảy ra theo đúng dự đoán của Pù Suô. Bằng sự nhạy cảm, nó dễ dàng nhận ra được những mâu thuẫn ngấm ngầm giữa hai con trâu trong đàn. Ở miền núi, những cuộc chiến giữa những con trâu đực xảy ra rất thường xuyên, đó là do ý muốn tranh giành sự bá chủ trong địa bàn hoặc đơn giản chỉ để phô trương sức mạnh vô địch. Sau cuộc huyết chiến giữa con Sừng Vênh và con Mộng Non, "Con Pù Suô không biết đang nghĩ gì, mà đầu cứ cúi gằm, chăm chỉ bước đi, không còn muốn vơ thêm ngọn cỏ nào nữa" $[4, \operatorname{tr} 17]$. Có điều gì đó như chững lại trong dòng suy nghĩ của bạn đọc về nỗi buồn của một con trâu từng trải này. Phải chăng đó là nỗi buồn rầu khi chứng kiến sự đấu đá mất đoàn kết trong nội bộ? Hay cuộc quyết chiến chống lại sự áp bức, bất công? Nhà văn Mã $\mathrm{A}$ Lềnh không bàn luận gì mà để ngỏ cho các bạn đọc nhỏ tuổi của chúng ta tự chiêm nghiệm và rút ra bài học cho chính bản thân mình về cách sống.

Nếu như Pù Suô được miêu tả với tính cách điềm đạm thì trong truyện Núi Cu Sú, Sừng Săn lại là một "chàng" trâu đầy bản lĩnh, mạnh mẽ như chính tuổi trẻ hừng hực của nó. Sừng Săn là con của Pù Suô, là một "chàng trâu hoàn hảo". Khi trưởng thành, Sừng Săn tráng kiện nhất làng. "Làng trên, làng dưới không ai có con trâu đẹp mà khỏe như thế" [4, tr.28]. Giống như bao chú trâu đực hiếu chiến khác, Sừng Săn tham gia cuộc chiến đấu ba ngày ba đêm với con trâu nhà họ Cứ. Dù mang trong mình nhiều thương tích "Sừng Săn rách từng vệt da, bầm máu, đầu trụi thùi lụi không một sợi lông" [4, tr.28] nhưng "Trong ánh đuốc, đôi mắt nó long lanh ra vẻ hãnh diện lắm" [4, tr 29]. Mã $\mathrm{A}$ Lềnh đặc biệt nhấn mạnh đến sự dũng cảm của Sừng Săn khi nhắc đến chiến công giết hổ của nó trên núi $\mathrm{Cu}$ Sú. "Một cảnh tượng rùng rợn diễn ra: Sừng Săn cong lưng, ghì mình xiết chặt con hổ vằn lên vách đá, chốc chốc, lại thở phì phì" [4, tr.30]. Trong cuộc chiến không cân sức đó, Sừng Săn đã chiến thắng kẻ thù bằng sức mạnh và sự khéo léo.

Độc đáo hơn cả là tính cách mạnh mẽ và bướng bỉnh của chú ngựa Mun trong truyện "Con ngựa mun cuối cùng thuộc dòng dõi quý tộc". Nó là một con ngựa đực, khá đặc biệt: màu mun, đầu nhỏ, ức nở nang, bụng thon, vó nhỏ cắm xuống, chân chụm, bước chân sau cắm đúng vào vết chân trước. Trên lưng nó đáng lẽ là một chiến binh lẫy lừng thiên hạ để sánh với tư cách dũng mãnh của nó nhưng vì sinh nhầm thời và nhầm chỗ nên thành một con ngựa thồ hàng "bê bết 
cứt đái”, với hai cái sảo méo mó kẹp hai bên. Nó phản kháng bằng những cuộc quấy phá, chạy lồng và “....nó phải chịu những trận đòn roi của bố thằng Sồng rồi những chuyến đi dân công thồ đá làm mương thủy lợi, rồi những cuộc ẩu đả khi đang thả rông, hay khi đang bị buộc bên lề đường vào chợ, và cả những cuộc giao phối bạo liệt nữa..." [3, tr.47]. Cuối cùng khi đã gần kề cái chết, con ngựa Mun lại nhận được sự cứu vớt của Thạch Mã và nhận được sự trân trọng đúng với giá trị thật sự của nó "Đến địa phận đất nhà tôi, bỗng dưng nó cất tiếng hí vang trời” [3, tr.50].

Con Cộc trong truyện ngắn Đi săn được Mã A Lềnh khắc hoạ sinh động. Vốn thuộc nòi chó săn, tài năng của con Cộc được ghi nhận bằng những chiến công mà nó đạt được. “Chiến công của nó, nếu như Vư không lưu giữ được thì không thể biết hết, đó là những cái rănh nanh, răng hàm, khúc xương, túm lông hoặc là chút máu được bôi lại trên một cây gậy”[4, tr.9]. Trong cuộc đi săn nào nó cũng giữ vai trò chính, khi thì lôi được một con trăn to bằng bắp tay về, khi thì lừa được một con lợn rừng chạy vào mắc kẹt trong khe đá. Lần đi săn này, Cộc lại lập được chiến công đầu nên được chia phần rất hậu hĩnh “.... một xâu thịt lớn, có cả xương thủ, xương sống, xương cẳng, một khúc đuôi, một khúc lòng, miếng tim, gan, phổi” [4, tr.12]. Thế là trên vách liếp nhà Vư, lại có thêm một chiếc răng nanh lợn lòi. Tuy Cộc ta trông giống với một con sói nhưng lại có những lúc yếu mềm, động lòng trắc ẩn. Một lần, Cộc phát hiện được một ổ dúi, "một con dúi mẹ đang ấp ủ một đàn con, con nào con nấy lông mượt vàng, tròn lẳn như những chú gà nhép mới nở. Chẳng hiểu sao Cộc ta lại lẳng lặng bỏ đi” [4, tr.9]. Hình ảnh chú chó hiện lên thật nhân ái và hào hiệp. Câu chuyện giống như một bài học về lòng yêu thương, sự đồng cảm được kể một cách tự nhiên, nhẹ nhàng, sâu lắng. Truyện ngắn viết cho thiếu nhi của mã $\mathrm{A}$ Lềnh đã đem lại nhiều bài học giá trị góp phần giáo dục đạo đức, hình thành nhân cách tốt đẹp cho trẻ em, đặc biệt là các em nhỏ miền núi, vùng dân tộc thiểu số.

Không chỉ trong sáng tác của nhà văn người Mông Mã A Lềnh, trong một số truyện ngắn của các tác giả dân tộc Tày, con trâu cũng xuất hiện, trở thành con vật gần gũi, thân quen, và là người bạn gắn bó với tuổi thơ của các em. Trong Thách đố, Vi Hồng đã miêu tả rất thành công tình cảm của cậu bé Hoàng với chú nghé tội nghiệp. Từ một con nghé bị "nhan" (ghẻ) cắn lở loét, bẩn thỉu sắp bị đem chôn, nhờ bàn tay chăm sóc của Hoàng, con nghé đã "hồi sinh" trở thành chàng trâu đực Vài Mu khỏe mạnh, dũng mãnh: "Vài $\mathrm{Mu}$ có tấm ngực nở, rộng thênh, chân to như cột nhà, đi đứng vững như cột đá. Cặp sừng cong như hai vành trăng khuyết. Gốc sừng to bè, mập mạp. Ngọn sừng nhọn như mũi giáo" [1, tr.23]. Vai Mu không chỉ là con trâu khỏe mạnh, dai sức, làm việc tốt mà nó còn là con vật nghĩa tình, có nhận thức. Khi làm việc có lỗi nó biết "run sợ, cúp đuôi, co mình lại, run cầm cập như một con cún con" [1, tr.33]. Nó cũng biết thể hiện tình cảm nhớ thương dành cho chủ: "Con Vài $\mathrm{Mu}$ chạy đến trước mặt Hoàng. Một chân nó quỳ xuống, một chân sau duỗi ra, quệt quệt vào đất. Miệng nó "ngá ọ" từng tiếng khe khẽ. (...). Hai giọt nước mắt rất to lăn khỏi mí mắt trâu Vài Mu. Rồi hai giọt nữa, hai giọt nữa..." [1; tr.57 - 58]. Và Vài Mu cũng biết tỏ ra vui sướng, bẽn lẽn khi được khen: "Hoàng cứ thế mà reo hò. Trâu Vài $\mathrm{Mu}$ cười nhe cả lợi sún. Một chân nó quệt quệt xuống đất...” [1, tr.93]. Khỏe mạnh, khôn ngoan, dũng mãnh, nghĩa tình, Vài $\mathrm{Mu}$ dành được nhiều yêu mến của độc giả nhỏ tuổi.

Trong truyện ngắn của Đoàn Lư (Con Mốc của bác Luồng), chú chó có cái tên rất đỗi quê mùa được tác giả miêu tả với một giọng văn dí dỏm: “Chàng Mốc không phải loại điển trai nhưng vóc dáng cao lớn, hoạt bát, khỏe mạnh, tai hơi cụp nhưng tinh ranh đáo để nhiều cô bạn không ưa bộ lông mốc thếch của nó, nhưng không cưỡng lại được cái tính khảng khái, hào hiệp và dáng dấp hùng dũng của anh chàng Mốc" [7, tr.10]. Mốc hiện lên với dáng vẻ của một chàng thanh niên mới lớn khiến cho độc giả thấy vô cùng thú vị. Đặc biệt Mốc lại vô cùng thông minh và có phần“tinh ranh”, đây là cảnh chú ta rình đàn khỉ đang phá nương ngô: "Con Mốc tính toán, rồi nó vụt chạy về phía bờ sông, vừa đi vừa sủa "ốp, ốp, ốp" giả đò như mải đuổi theo con thú nào khác, rời xa đàn khỉ. Thế rồi nó lặng lẽ đi vòng trở lại, nó tiến lại mỏm đá từ phía đằng sau. (...) Bập! Hai hàm đầy răng của con Mốc cắn vào bàn tay lông lá của lão khỉ già, khiến nó kêu thất thanh, thả mình rơi xuống như một quả bưởi rụng" [7, tr.13]. Cách miêu tả dí dỏm, độc đáo, cộng với nghệ thuật nhân hóa đã tạo nên được hình ảnh đầy ấn tượng của chú chó Mốc.

Trong Quái cẩu Pi - tơ - chun, Đoàn Lư cũng để chú chó thông minh Pi - tơ - chun tự kể lại câu chuyện của cuộc đời mình. Vốn "sinh ra ở thành phố Đà Lạt mộng mơ" [8, tr.3] và có cuộc sống êm đềm bên ông bà chủ là những người rất yêu thương loài vật. Nhưng 
sóng gió đã ập đến với “cuộc đời” Pi kể từ khi ông bà chủ của chú mất vì tai nạn giao thông. Không còn người thân, không nơi nương tựa, Pi lưu lạc nhiều nơi. Bị bọn trộm chó bắt cóc bán cho Chiêu Pán (một tên người Trung Quốc ác độc), bị hắn bắt làm nhiều trò ác độc, Pi bỏ trốn và may mắn gặp được ngài $\mathrm{Pi}$ - tơ - li, một thương gia giàu có và hiểu biết, kể từ đó chú đã lập được nhiều kì tích trở thành một "siêu khuyển" nổi tiếng với trí tuệ và tài năng hơn người. Trong tác phẩm, tác giả đã để Pi tự bộc lộ những phẩm chất của bản thân mình: kiêu hãnh về tài năng, tự hào về phẩm chất, giàu lòng tự trọng, ý chí kiên định, tài năng và trí tuệ siêu phàm. Được viết bởi lối văn giả tưởng, câu chuyện cuộc đời Pi đã mở ra một thế giới mới mẻ hấp dẫn các độc giả nhí.

Có thể nói rằng, trong sáng tác của các nhà văn dân tộc thiểu số, người trần thuật đã hóa thân vào nhiều con vật khác nhau và đối với mỗi kiểu nhân vật đó, các nhà văn có cách khai thác vô cùng thú vị. Mỗi con vật đều có những nét tính cách riêng, có suy nghĩ, hoài bão, ước mơ. Nhân vật chú khỉ King (Cuộc phiêu lưu của khỉ con), và chàng tê tê Xuyên Sơn (Ly kì Xuyên Sơn) thuộc "kiểu người" ưu mạo hiểm và thích khám phá. Sinh ra trong rạp xiếc, dù được yêu mến và quan tâm nhưng trong lòng khỉ King vẫn luôn đau đáu khát vọng được khám phá thế giới: “Cái đầu nó thường mơ đến những bến bờ xa lạ, đôi chân nó muốn đi đến cuối đất cùng trời. Tuy nhiều nơi King đã được đặt chân tới, nhưng nó biết thế giới này còn rộng lắm" $[6$, tr.7]. Còn chú tê tê Xuyên Sơn trong một lần tò mò xen lẫn nghịch ngơm, Xuyên Sơn đã đào thủng cả lòng sông và nhờ đó đã vô tình tìm ra một hồ nước mênh mông trong lòng đất. Những nhân vật như chó Giôn và mèo Miu (Giôn và Miu), chim sáo (Mơ ước tốt lành) lại giàu chất suy tưởng. Giôn và Miu luôn băn khoăn vì sao những thành viên trong gia đình nhà chủ của chúng lại đối xử không tốt với nhau. Chim sáo nhỏ sau những biến cố mà bản thân trải qua thì lại đau đáu trong lòng suy nghĩ "tại sao nhiều người lại thích bắn giết loài chim đến thế”. Bài học về đạo đức sống và tình cảm gia đình cũng như lời nhắc nhở hãy yêu thương bảo vệ các loài vật hiền lành nhỏ bé đã cảnh tỉnh nhiều độc giả nhỏ tuổi một cách thú vị và sâu sắc. Chú vẹt (Chuyện anh vẹt xám) thì luôn kiêu hãnh và tự hào vì chú có xuất thân từ "một giống vẹt thông minh nhất trong các loài động vật” [7, tr.24]. Thậm chí đến cả chuột Cống (Giấc mơ của anh chuột Cống) cũng biết mơ ước: “Anh Cống dù thuộc diện to lớn, nếu so với họ hàng nhà chuột nhắt thì anh ta là chuột khổng lồ, nhưng so với nhiều loài vật khác thì anh ta chưa là gì cả. Đấy là nói đến thân xác, chứ nói đến trí tuệ thì loài chuột cống khuya mới có thể ngang bằng chó mèo... được. Nghĩ đến điều này Cống chỉ muốn chết quách đi cho xong, trời chẳng công bằng chút nào cả. Chính vì vậy ngày nào Cống cũng mơ ước làm sao có một sự đổi mới” [7, tr.14].

Cánh Cam (Cánh Cam kiêu sa) là một cô bé rất nhút nhát hiền lành khi còn nhỏ, nhưng lớn lên lại “trở nên kiêu sa, thậm chí muốn bất chấp tất cả. Sáng nào cũng vậy, khi chị Nắng ló khỏi ngọn tre đến bên cây Chanh Yên, Cánh Cam mới vươn vai xòe đôi cánh nâu bóng" [2, tr.457]. Cánh cam vì quá tự hào về bộ cánh xinh đẹp của mình nên chỉ ham chơi, chải chuốt, quên đi nhiệm vụ học tập và lao động. Hình ảnh Cánh Cam có chút gì đó rất gần với sự nổi loạn của tuổi mới lớn. Nói chuyện Cánh Cam, nhưng qua đó tác giả muốn nhắn nhủ bạn đọc của mình đừng như Cánh Cam vì bộ cánh đẹp không phải là thứ giá trị vĩnh cửu. Mèo con đi dự hội lại là một câu chuyện về việc tôn trọng lời hứa, giống như Mèo Con, các em nhỏ đã hứa là phải làm bởi "người không giữ đúng lời hứa là người xấu đấy” [2, tr.450].

Qua những câu chuyện về loài vật, các tác giả đã mang lại cho độc giả những trải nghiệm thú vị. Đó là hình ảnh trâu Vài Mu dũng cảm, tình nghĩa, chú chó Mốc tinh khôn, chó Pi tài năng, thích phiêu lưu, Xuyên Sơn dũng cảm xuyên qua lòng đất, chuột Cống háo danh mà ngu ngốc, Cánh Cam xinh đẹp mà lười biếng, Mèo Con biết tôn trọng lời hứa... Những trải nghiệm ấy sẽ trở thành những kỉ niệm khó quên đối với các em nhỏ yêu văn học. Đó cũng là những bài học bổ ích giáo dục cho các em về lẽ phải và cách làm người sâu sắc và ý nghĩa.

4. Bằng tâm huyết và cả sự trải nghiệm tuổi thơ của chính mình, các tác giả dân tộc thiểu số đã đem đến cho các em thiếu nhi những hình ảnh thú vị về một thế giới vô cùng hấp dẫn với các con vật thông minh, ngộ nghĩnh, đáng yêu. Trong truyện viết cho thiếu nhi của một số tác giả tiêu biểu như: Mã $\mathrm{A}$ Lềnh, Vi Hồng, Đoàn Lư, Hà Lâm Kỳ..., độc giả nhỏ tuổi tìm thấy cho mình những bài học bổ ích, sâu sắc về tình yêu loài vật, con người, tình yêu lao động và những trải nghiệm thú vị với những kỉ niệm khó quên. Đó cũng là những bài học giáo dục cho các em về lẽ phải và cách làm người sâu sắc, ý nghĩa. Đây có thể coi là nguồn tài liệu phong phú, 
đa dạng cho các cấp Tiểu học và Mầm non ở các địa phương miền núi phía Bắc. Tuy nhiên, hiện nay nguồn tư liệu này chưa được chú trọng để đưa vào tiếp nhận trong các nhà trường phổ thông. Hi vọng có dịp chúng tôi sẽ trở lại vấn đề này trong một bài viết khác.

\section{TÀI LIỆU THAM KHẢO}

(Chú thích: Nghiên cứu này nằm trong đề tài $\mathrm{KH}$ \& CN cấp Bộ, mã số: B2015 - TN 03 - 05)

1. Vi Hồng, Thách đố, Nxb Kim Đồng, Hà Nội, 1995 ;

2. Hà Lâm Kỳ, Văn xuôi Hà Lâm Kỳ, Nxb Hội nhà văn, Hà Nội, 2014;
3. Mã A Lềnh, Dấu chân trên đường, (tập truyện), Nxb Kim Đồng, Hà Nội, 1996;

4. Mã A Lềnh, Làng mình, (tập truyện), Nxb Kim Đồng, Hà Nội, 2008;

5. Lã Thị Bắc Lý, bài: Văn học thiếu nhi Việt Nam tù thời ki đổi mói, in trong cuốn: Văn học Việt Nam sau 1975 nhũng vấn đề nghiên cưu và giảng dạy, $\mathrm{Nxb}$ Giáo dục, 2006;

6. Đoàn Lư, Ly Kì xuyên son, Nxb Kim Đồng, Hà Nội, 2013;

7. Đoàn Lư, Tuoóng cuớp hoàn luoong (tập truyện), Nxb Kim Đồng, Hà Nội, 1997;

8. Đoàn Lư, Quái cẩu Pi - to - chun, Nxb Kim Đồng, Hà Nội, 1999;

9. Lâm Tiến, Tiếp cận văn học dân tộc thiểu số, Nxb Văn hóa Thông tin, Hà Nội, 2011.

\section{The animal world in stories for childrenof some ethnic minority writers in Vietnam}

\section{Cao Thi Hao}

\begin{tabular}{l}
\hline \multicolumn{1}{c}{ Article info } \\
\hline Recieved: \\
06/02/2018 \\
Accepted: \\
10/3/2018 \\
\hline
\end{tabular}

\section{Keywords:}

Ethnic minority literature;

Literature for children;

Children education;

World of animals.

\footnotetext{
Abstract

The article examines the contribution of some ethnic minority writers to the literature for children when writing about the animal world that is close to children in mountainous areas. These ethnic minority writers have brought in their writings the most characteristic features of the mountainous landscape and people, especially the close and lovely world of animals. In stories for children of some typical writers such as Ma ALenh, Vi Hong, Doan Lu, etc., young readers can find themselves with useful lessons, deep love for animals, humans, labor, enjoyable experience and unforgettable memories. These are also meaningful lessons for children about the right and how to be good men. This can be considered as a rich and diverse source for nursery and primary schools in the northern mountainous areas. However, this source of materials has not been paid much attention for adoption at high schools.
} 